\title{
Article \\ Fabrication and Characterization of Nanonet-Channel LTPS TFTs Using a Nanosphere-Assisted Patterning Technique
}

\author{
Gilsang Yoon ${ }^{1}\left[\right.$, Donghoon Kim ${ }^{1}$, Iksoo Park ${ }^{1}$, Bo Jin ${ }^{1, *}$ and Jeong-Soo Lee ${ }^{1,2, *}$ \\ 1 Department of Electrical Engineering, Pohang University of Science and Technology, Pohang 37673, Korea; \\ ygs6233@postech.ac.kr (G.Y.); kdong620@postech.ac.kr (D.K.); is.park@postech.ac.kr (I.P.) \\ 2 Division of IT Convergence Engineering, Pohang University of Science and Technology, Pohang 37673, Korea \\ * Correspondence: shengzhi86@postech.ac.kr (B.J.); ljs6951@postech.ac.kr (J.-S.L.); Tel.: +82-54-279-2380 (J.-S.L.)
}

Citation: Yoon, G.; Kim, D.; Park, I.; Jin, B.; Lee, J.-S. Fabrication and Characterization of Nanonet-Channel LTPS TFTs Using a

Nanosphere-Assisted Patterning Technique. Micromachines 2021, 12, 741. https://doi.org/10.3390/ mi12070741

Academic Editor: Hyuck-In Kwon

Received: 20 May 2021

Accepted: 20 June 2021

Published: 24 June 2021

Publisher's Note: MDPI stays neutral with regard to jurisdictional claims in published maps and institutional affiliations.

Copyright: (C) 2021 by the authors. Licensee MDPI, Basel, Switzerland. This article is an open access article distributed under the terms and conditions of the Creative Commons Attribution (CC BY) license (https:// creativecommons.org/licenses/by/ $4.0 /)$.
Abstract: We present the fabrication and electrical characteristics of nanonet-channel (NET) lowtemperature polysilicon channel (LTPS) thin-film transistors (TFTs) using a nanosphere-assisted patterning (NAP) technique. The NAP technique is introduced to form a nanonet-channel instead of the electron beam lithography (EBL) or conventional photolithography method. The size and space of the holes in the nanonet structure are well controlled by oxygen plasma treatment and a metal lift-off process. The nanonet-channel TFTs show improved electrical characteristics in terms of the ION/IOFF, threshold voltage, and subthreshold swing compared with conventional planar devices. The nanonet-channel devices also show a high immunity to hot-carrier injection and a lower variation of electrical characteristics. The standard deviation of $\mathrm{VTH}(\sigma \mathrm{VTH})$ is reduced by $33 \%$ for a nanonet-channel device with a gate length of $3 \mu \mathrm{m}$, which is mainly attributed to the reduction of the grain boundary traps and enhanced gate controllability. These results suggest that the cost-effective NAP technique is promising for manufacturing high-performance nanonet-channel LTPS TFTs with lower electrical variations.

Keywords: grain boundary traps; polysilicon; nanonet-channel; nanosphere-assisted patterning; thin-film transistors

\section{Introduction}

Polysilicon thin-film transistors (poly-Si TFTs) have been widely used in flat panel displays, image sensors, and 3D memory devices [1-10]. However, the inherent grain boundary (GB) in the poly-Si layer can significantly affect the electrical behaviors and reliability characteristics. The acceptor-like or donor-like traps in GBs can cause potentialbarrier fluctuations and interrupt the carrier flow in the channel [11,12]. Another important issue is the non-uniformity of the electrical performance caused by the size, number, and quality of GBs varied from device to device and wafer to wafer $[13,14]$. In order to mitigate the effect of GB traps, a thermal post-annealing process and a modulated excimer-laser method were reported [15-19].

Recently, a macaroni channel structure demonstrated an improved performance for 3D memory devices. The core poly-Si channel was etched out and filled with a dielectric. The improved performance was mainly due to the reduced GB traps and the effect of the thinbody channel [20]. More recently, nanonet-channel TFTs were successfully demonstrated. Hexagonal holes with various pattern sizes and distances between patterns were formed in the poly-Si channel region using electron beam lithography (EBL). As a result of the effective reduction of grain boundary traps and enhanced gate controllability, the nanonetchannel TFTs showed a better subthreshold swing (SS), lower threshold voltage $\left(\mathrm{V}_{\mathrm{TH}}\right)$, and higher ON-OFF current ratio ( $\mathrm{I}_{\mathrm{ON}} / \mathrm{I}_{\mathrm{OFF}}$ ) compared with conventional planar TFTs [21,22]. However, for large-area applications of nanonet-channel devices, an alternative lithography method with a relatively cheap and high through-put is inevitably required. 
Here, a nanosphere-assisted patterning (NAP) technique involving oxygen plasma treatment has been developed to form the nanonet structure. The NAP technique with the advantages of inexpensive equipment and the capability of large-area patterning, has been widely used to realize periodic photonic devices [23,24], solar cell [25], biological devices [26,27], and electrical sensors [28,29].

We demonstrated nanonet-channel low-temperature polysilicon (LTPS) thin-film transistors (TFTs) using the NAP technique. The DC performance and reliability were characterized and compared with those of conventional planar devices. The impact of the nanonet-channel on the variation of electrical characteristics was also investigated.

\section{Experimental Details}

Nanonet-channel LTPS TFTs (NET_TFTs) and conventional planar TFTs (CON_TFTs) were fabricated on an LTPS-on-glass substrate. The LTPS was prepared by depositing an amorphous Si using a low-pressure chemical vapor deposition (LPCVD) at $550{ }^{\circ} \mathrm{C}$ and a subsequent excimer laser annealing (ELA) process. The grain size and thickness of the poly-Si were about 200-400 $\mathrm{nm}$ and $50 \mathrm{~nm}$, respectively [21,22]. Both devices underwent the same process steps, except for the nanonet structure formation processes. Figure 1 shows a schematic diagram of the process flow of the nanonet-channel devices using the NAP technique. First, a mask aligner and an inductively coupled plasma (ICP) dry etcher were used to define the source and drain (S/D) regions (Figure 1a). Next, a 20-nm $\mathrm{SiO}_{2}$ isolation layer was deposited by plasma-enhanced chemical vapor deposition (PECVD) (Figure $1 \mathrm{~b}$ ). A monolayer of polystyrene nanospheres (PNs) was uniformly formed on the isolation layer by a spin coating process, and then, the $\mathrm{O}_{2}$ plasma treatment was performed to control the size of the PNs (Figure 1c,d). Then, a perforated metal film with a nanohole pattern was formed by a lift-off process. A hard mask was formed on the S/D region using a mask aligner, and the isolation layer and LTPS were etched using an ICP etcher. All of the hard mask layers were then removed (Figure 1e-g). Next, a 100-nm $\mathrm{SiO}_{2}$ gate oxide layer was deposited using PECVD, and Mo was deposited as a gate electrode, followed by patterning using an ICP etcher. Next, the $\mathrm{S} / \mathrm{D}$ regions were implanted with phosphorus (20 keV at $2 \times 10^{15} \mathrm{~cm}^{-2}$ ), and rapid thermal annealing was performed (Figure 1h). Finally, $\mathrm{Ti} / \mathrm{Ag}(500 \mathrm{~nm} / 2000 \mathrm{~nm})$ interconnection metal films were deposited and forming gas annealing was performed at $450{ }^{\circ} \mathrm{C}$ for $30 \mathrm{~min}$.

Figure 2 shows the dependence of the diameter of the $\mathrm{PNs}$ on the $\mathrm{O}_{2}$ plasma treatment. The plasma parameters used were an RF power of $50 \mathrm{~W}, \mathrm{O}_{2}$ flow rate of $50 \mathrm{sccm}$, and chamber pressure of 450 mTorr. The nanosphere size was adjusted by increasing the $\mathrm{O}_{2}$ plasma etching time. The diameter of the PNs decreased slowly and then rapidly after 1 min of etching time, which can determine the hole pattern size $\left(\mathrm{W}_{\mathrm{H}}\right)$ and distance between patterns $\left(\mathrm{W}_{\mathrm{D}}\right)$ in the nanonet-channel region. The plasma treatment time of $85 \mathrm{~s}$ was used to form the reproducible nanonet structures.

Both the NET_TFTs and CON_TFTs had gate lengths ( $\mathrm{L}_{\mathrm{GATE}}$ ) of 3, 6, or $10 \mu \mathrm{m}$ and a width $\left(\mathrm{W}_{\mathrm{GATE}}\right)$ of $5 \mu \mathrm{m}$. In the NET_TFTs, the hole size $\left(\mathrm{W}_{\mathrm{H}}\right)$ and the distance between holes $\left(W_{\mathrm{D}}\right)$ in the nanonet-channel region were fixed at $320 \mathrm{~nm}$ and $130 \mathrm{~nm}$, respectively. The electrical characteristics and hot-carrier injection (HCI) were measured using a semiconductor parameter analyzer (Keithley 4200). 
(a) Active region patterning

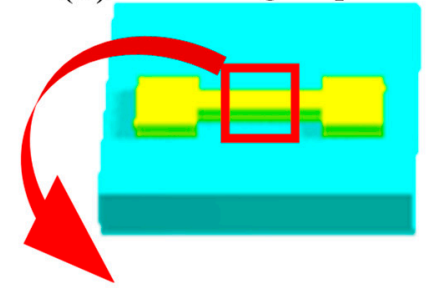

Nanosphere assisted patterning

(b) Oxide deposition

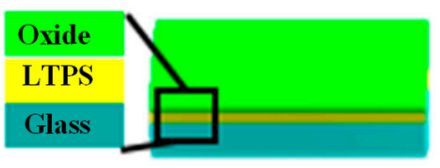

(d) $\mathrm{O}_{2}$ plasma etching \& Metal evaporation

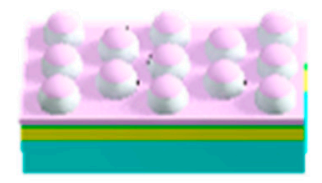

(f) Dry etching (Oxide, LTPS)

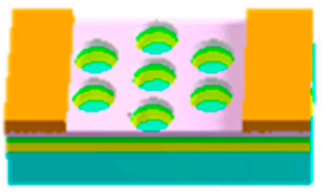

(c) As-spin coated nanospheres

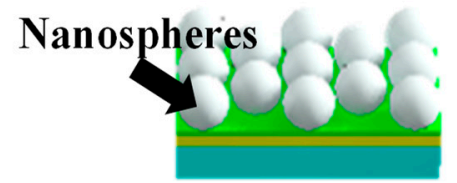

(e) Nanospheres lift-off \& PR patterning

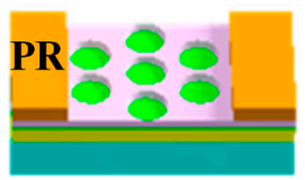

(g) Remove all hard mask layers

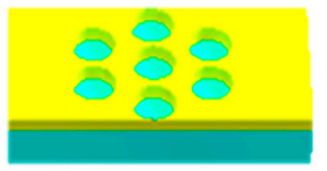

(h) Gate stack formation \& IIP \& Annealing

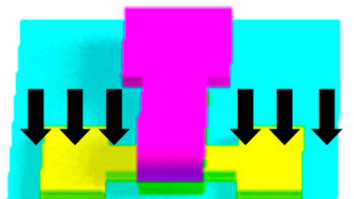

Phosphorus

(20 Kev, $2 \times 10^{15} \mathrm{~cm}^{-2}$ ) (i) S/D contact pad formation

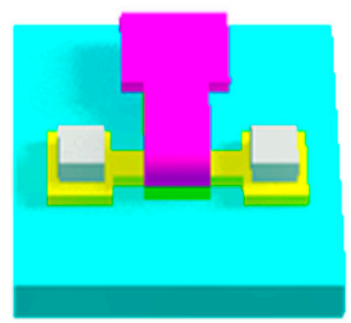

Figure 1. Schematic diagram of fabrication steps of nanonet-channel thin-film transistors (TFTs) using the nanosphere-assisted patterning (NAP) technique. 


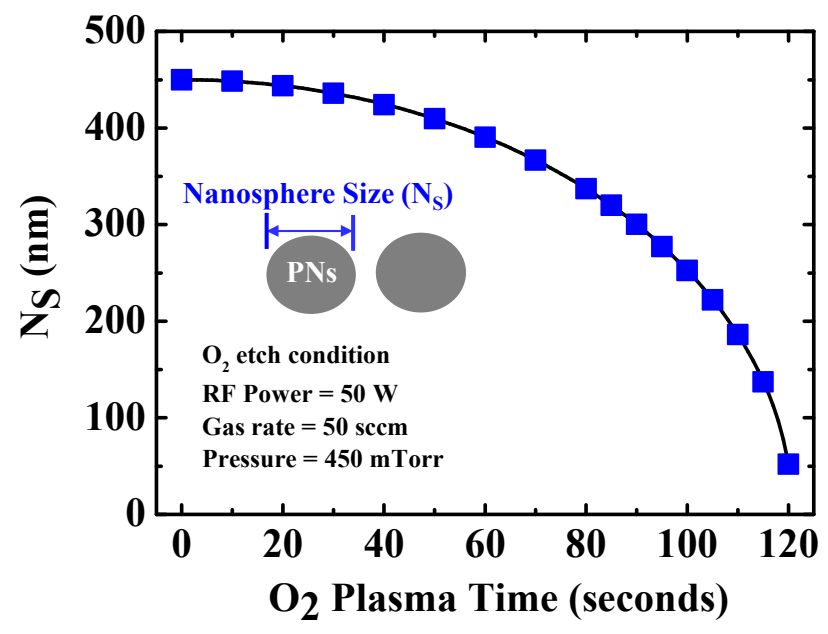

Figure 2. Size of the polystyrene nanosphere as a function of $\mathrm{O}_{2}$ plasma exposure time.

\section{Results and Discussions}

Figure 3a shows the scanning electron microscope (SEM) images of the spin-coated PNs on the substrate, where 450-nm PNs are uniformly arranged. After the NAP process (Figure $1 \mathrm{~g}$ ), nanonet patterns were successfully formed onto the LTPS layer with a $\mathrm{W}_{\mathrm{H}}$ of $320 \mathrm{~nm}$ and $W_{D}$ of $130 \mathrm{~nm}$, as shown in Figure 3b.

(a)

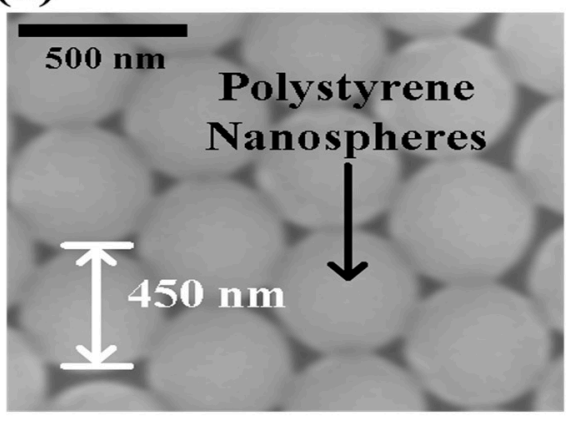

(b)

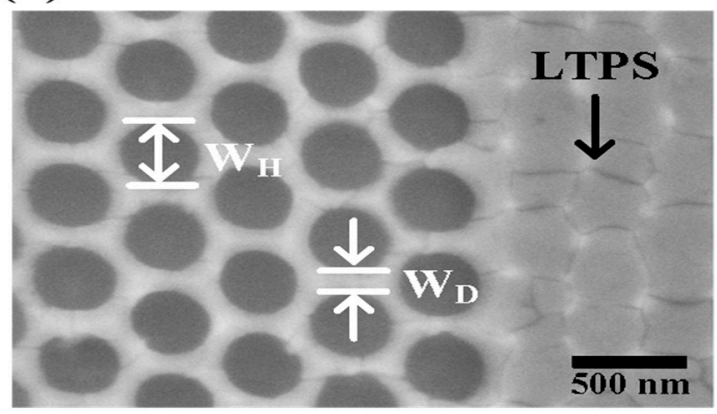

Figure 3. Top SEM images of (a) spin coated nanosphere after Figure 1c and (b) nanonet-channel after Figure 1g.

The initial channel volume $\left(W_{G A T E} \times L_{G A T E} \times T_{S i}\right)$ was the same in both CON_TFTs and NET_TFTs, as shown in Figure 4 . The threshold voltage $\left(V_{T H}{ }_{C} C O N\right)$ was dependent on the total number of traps related to the channel volume, as follows [20]:

$$
V_{T H_{-} C O N} \approx V_{F B}+2 \varnothing_{F}+\frac{q N_{\text {trap }}}{C_{O X}}\left(W_{G A T E} \cdot L_{G A T E}\right) \cdot T_{S i}
$$

where $q$ is the electric charge, $C_{O X}$ is the gate-oxide capacitance, $N_{\text {trap }}$ is the total number of traps per unit volume, and $T_{s i}$ is the channel thickness.

\section{Conventional}

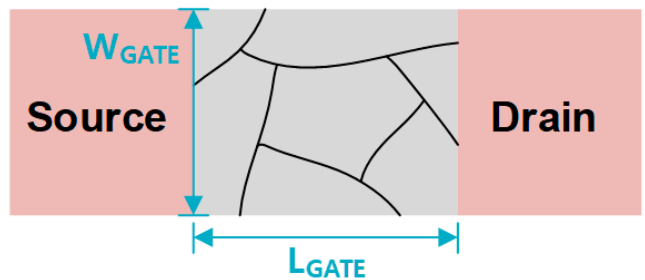

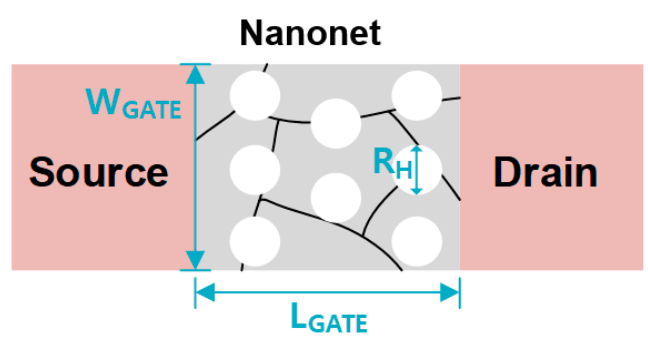

Figure 4. Top-view scheme of conventional planar TFTs (CON_TFTs) (left) and nanonet-channel low-temperature polysilicon TFTs (NET_TFTs) (right). 
The lowering of the threshold voltage $\left(V_{T H_{-} N E T}\right)$ using the nanonet channel is described as follows:

$$
V_{T H \_N E T} \approx V_{F B}+2 \varnothing_{F}+\frac{q N_{\text {trap }}}{C_{O X}}\left(W_{G A T E} \cdot L_{G A T E}-N_{H} \cdot \pi R_{H}\right) \cdot T_{s i}
$$

where $N_{H}$ is a number of holes in the nanonet channel and $R_{H}$ is a diameter of the hole.

Compared with the planar device, the nanonet-channel device can lower the threshold voltage by decreasing the total traps. Furthermore, the tri-gate effect between the holes in the nanonet channel can improve the electrical characteristics as a result of the enhanced gate controllability $[21,22,30]$.

Figure 5 shows the measured DC characteristics of both NET_TFTs and CON_TFTs at room temperature. The ON-state current $\left(\mathrm{I}_{\mathrm{ON}}\right)$ and the OFF-state minimum leakage current ( $\mathrm{I}_{\mathrm{OFF}}$ ) were measured at $\mathrm{V}_{\mathrm{G}}-\mathrm{V}_{\mathrm{TH}}=3 \mathrm{~V}$ and $-5 \mathrm{~V}$ with $\mathrm{V}_{\mathrm{D}}=1 \mathrm{~V}$, respectively. The threshold voltage was extracted using the linear extrapolation method [31]. The subthreshold slope was calculated as $\left[d\left(\log _{10} I_{D}\right) / d \mathrm{~V}_{\mathrm{G}}\right]^{-1}$. As $\mathrm{L}_{\mathrm{GATE}}$ decreased, both devices showed an improved performance mainly due to the lower GB traps at shorter channel lengths [32]. Compared with the CON_TFTs, NET_TFTs showed a higher I IN $/ \mathrm{I}_{\mathrm{OFF}}$ and $\mu^{*} \mathrm{FE}$, and lower SS and $\mathrm{V}_{\mathrm{TH}}$, which was similar to previous results obtained using EBL technique [21,22]. The mean drain-induced barrier lowering (DIBL) with $L_{\text {GATE }}=3 \mu \mathrm{m}$ was $130 \mathrm{mV} / \mathrm{V}$ for NET_TFTs and $230 \mathrm{mV} / \mathrm{V}$ for CON_TFTs, respectively. The mean $\mu_{F E}^{*}\left(\equiv \mu_{F E} \times W_{G A T E} / L_{G A T E}=g_{m} \cdot\left(C_{O X} \cdot V_{D}\right)^{-1}\right)[21]$ and $\mathrm{I}_{\mathrm{ON}} / \mathrm{I}_{\mathrm{OFF}}$ of the NET_TFTs increased by $\sim 18 \%$ and $\sim 120 \%$ from $L_{G A T E}=10 \mu \mathrm{m}$ to $L_{G A T E}=3 \mu \mathrm{m}$, respectively.

(a)

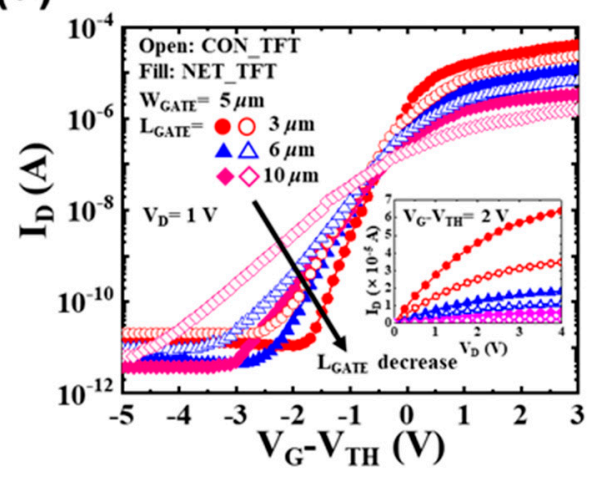

(c)

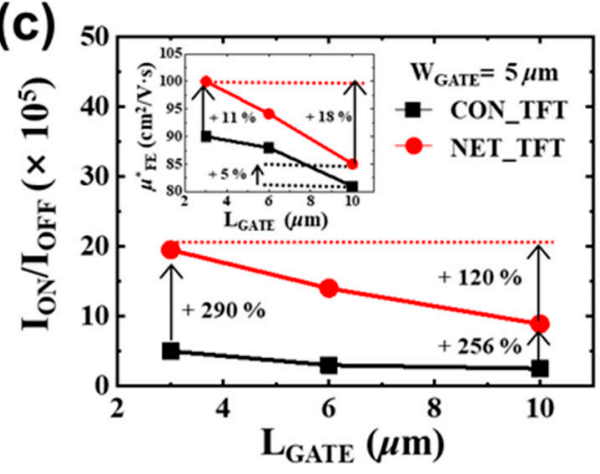

(b)

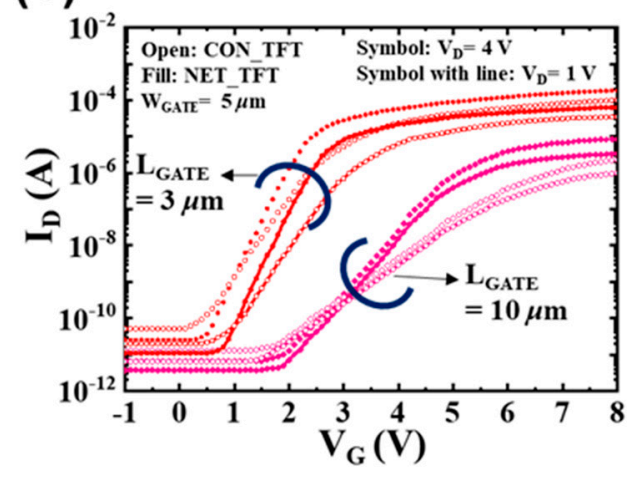

(d)

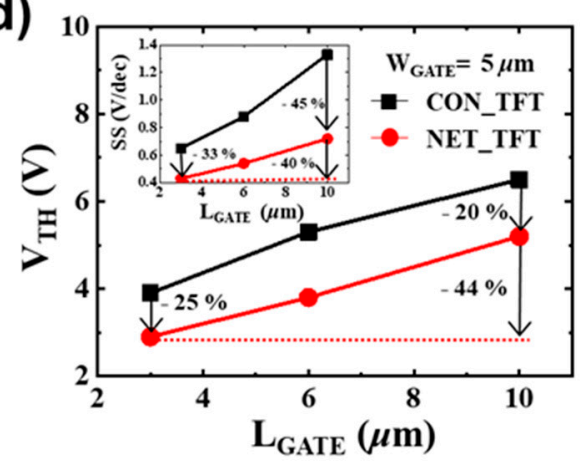

Figure 5. Comparison of the DC characteristics for NET_TFTs and CON_TFTs with different $\mathrm{L}_{\mathrm{GATE}}$ : (a) representative transfer curves $\left(I_{D}\right.$ vs. $\left.V_{G}-V_{T H}\right)$, (b) representative transfer curves with $V_{D}=1$ and $4 \mathrm{~V}$, (c) an average ON/OFF current ratio, and (d) an average $\mathrm{V}_{\mathrm{TH}}$. Insets show the measured output curves $\left(\mathrm{I}_{\mathrm{D}}\right.$ vs. $\left.\mathrm{V}_{\mathrm{D}}\right), \mu_{\mathrm{FE}}^{*}$, and $\mathrm{SS}$ as a function of $\mathrm{L}_{\mathrm{GATE}}$. 
At $L_{\text {GATE }}=3 \mu \mathrm{m}$, the mean SS and $\mathrm{V}_{\mathrm{TH}}$ of NET_TFTs were $\sim 33 \%$ and $25 \%$ lower, respectively, than those of CON_TFTs. Moreover, for all of the channels, the NET_TFTs had a higher $\mathrm{I}_{\mathrm{ON}} / \mathrm{I}_{\mathrm{OFF}}$ and $\mu_{\mathrm{FE}}^{*}$, improved SS, and lower $\mathrm{V}_{\mathrm{TH}}$ compared with CON_TFTs.

The grain boundary trap density $\left(N_{G B}\right)$ and interface trap density $\left(N_{I T}\right)$ were extracted to verify the influence of the nanonet-channel structure on the trap level in the polySi channel [32-35]. At $\mathrm{L}_{\mathrm{GATE}}=3 \mu \mathrm{m}$ and $\mathrm{W}_{\mathrm{H}}=320 \mathrm{~nm}$, the extracted $\mathrm{N}_{\mathrm{GB}}$ and $\mathrm{N}_{\mathrm{IT}}$ values were $9.8 \times 10^{11} \mathrm{~cm}^{-2}$ and $1.7 \times 10^{12} \mathrm{~cm}^{-2}$ for CON_TFT, and $5.4 \times 10^{11} \mathrm{~cm}^{-2}$ and $1.01 \times 10^{12} \mathrm{~cm}^{-2}$ for NET_TFT, respectively. As a result of the enhanced gate controllability and effective reduction of GB traps, NET_TFTs could provide a better interface quality and improved electrical characteristics [21,22]. Figure 6 shows the degradation of $\mathrm{V}_{\mathrm{TH}}$ and SS under $\mathrm{HCI}$ conditions at $\mathrm{V}_{\mathrm{G}}-\mathrm{V}_{\mathrm{TH}}=\mathrm{V}_{\mathrm{D}}=4 \mathrm{~V}$. The degradation is generally caused by trap-generation in GBs and at the oxide/channel interface under HC stress conditions [36]. Similar to previous results, NET_TFTs showed a higher immunity to HCI stress than CON_TFTs because of the effective reduction of GB traps in the nanonet-channel [21].

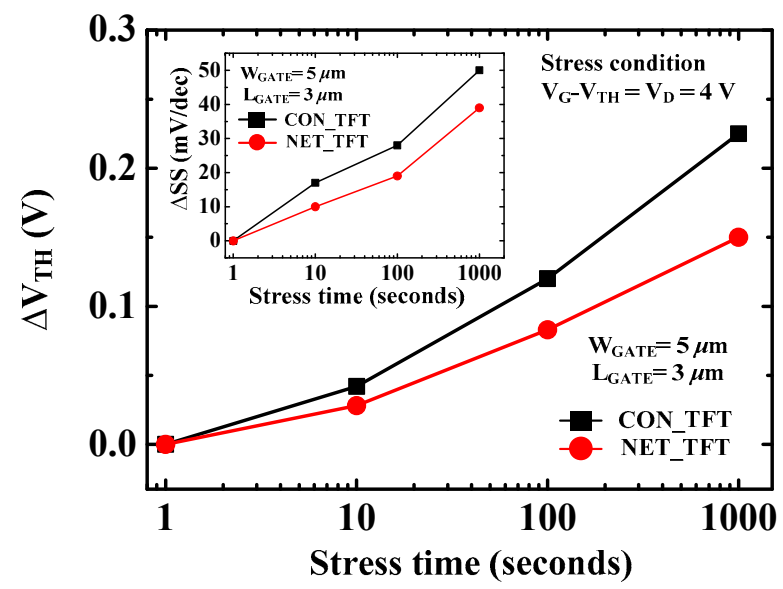

Figure 6. Measured $\Delta \mathrm{V}_{\mathrm{TH}}$ and $\Delta \mathrm{SS}$ (inset) for NET_TFT and CON_TFT with $\mathrm{L}_{\mathrm{GATE}}=3 \mu \mathrm{m}$ under an $\mathrm{HCI}$ stress condition at $\mathrm{V}_{\mathrm{G}}-\mathrm{V}_{\mathrm{TH}}=\mathrm{V}_{\mathrm{D}}=4 \mathrm{~V}$ during $0-1000 \mathrm{~s}$.

The variation of the electrical characteristics of both devices were investigated at room temperature. Figure 7 shows the cumulative distribution of SS and $\mathrm{V}_{\mathrm{TH}}$ for NET_TFTs and CON_TFTs with $\mathrm{L}_{\mathrm{GATE}}=3,6$, and $10 \mu \mathrm{m}$. The NET_TFTs showed lower variation compared with the CON_TFTs. The average and standard deviation of $S S$ and $V_{\mathrm{TH}}$ are shown in Table 1. As $L_{\text {GATE }}$ decreased, the standard deviation increased slightly for both devices, which is consistent with the results that the variation of electrical characteristics increased as the device shrank.

Table 1. Average and standard deviation of $\mathrm{V}_{\mathrm{TH}}$ and SS for NET_TFTs and CON_TFTs with different $\mathrm{L}_{\mathrm{GATE}}$.

\begin{tabular}{cccccc}
\hline $\begin{array}{c}\text { Channel } \\
\text { Structure }\end{array}$ & $\begin{array}{c}\mathbf{L}_{\text {GATE }} \\
{[\boldsymbol{\mu m}]}\end{array}$ & $\begin{array}{c}\text { AVG. } \\
{[\mathbf{V}]}\end{array}$ & $\begin{array}{c}\text { STD V } \\
{[\mathbf{V H}]}\end{array}$ & $\begin{array}{c}\text { AVG. SS } \\
{[\mathbf{V} / \mathbf{d e c}]}\end{array}$ & $\begin{array}{c}\text { STD SS } \\
{[\mathbf{V} / \mathbf{d e c}]}\end{array}$ \\
\hline \multirow{3}{*}{ conventional } & 3 & 3.9 & 0.43 & 0.65 & 0.20 \\
& 6 & 5.3 & 0.30 & 0.88 & 0.16 \\
& 10 & 6.5 & 0.23 & 1.33 & 0.15 \\
\hline \multirow{3}{*}{ nanonet } & 3 & 2.9 & 0.29 & 0.43 & 0.09 \\
& 6 & 3.8 & 0.20 & 0.54 & 0.08 \\
& 10 & 5.2 & 0.15 & 0.72 & 0.07 \\
\hline
\end{tabular}


(a)
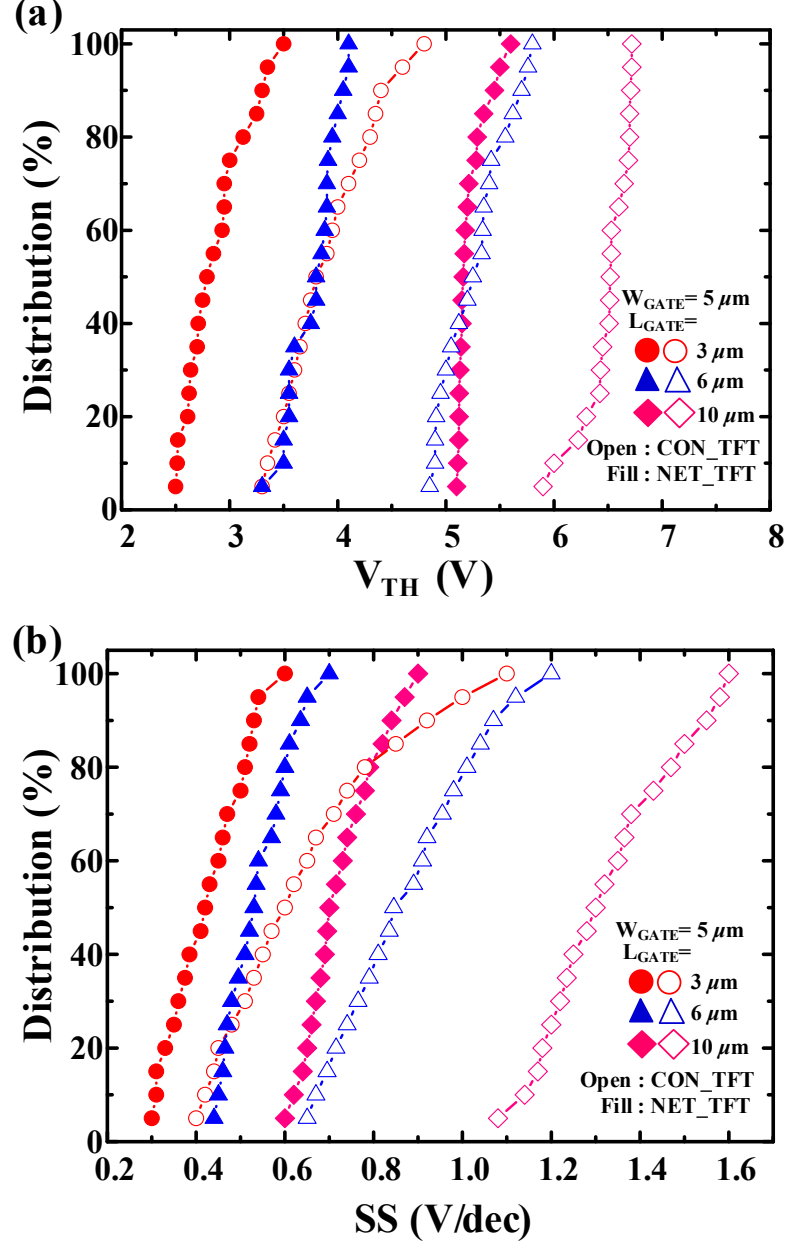

Figure 7. Cumulative distribution of (a) $\mathrm{V}_{\mathrm{TH}}$ and (b) SS for NET_TFT and CON_TFT (20 devices).

Figure 8 shows the standard deviation of $V_{T H}\left(\sigma V_{T H}\right)$ for both devices as a function of the device area $\left((L W)^{-1 / 2}\right) . \sigma \mathrm{V}_{\mathrm{TH}}$ can be expressed as follows [37]:

$$
\sigma V_{T H}=\frac{q}{C_{O X}} \sqrt{\frac{N_{E F F} W_{d e p}}{3 L W}}
$$

where $N_{E F F}$ is the effective concentration of channel doping, $W_{\text {dep }}$ is the depletion width of the channel, $L$ is the footprint length, and $W(=5 \mu \mathrm{m})$ is the foot-print width.

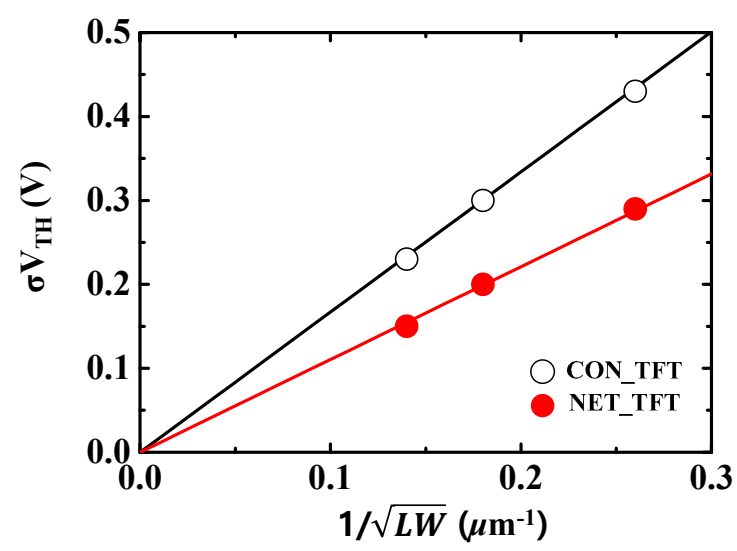

Figure 8. Standard deviation of $\mathrm{V}_{\mathrm{TH}}\left(\sigma \mathrm{V}_{\mathrm{TH}}\right)$ as a function of $L W^{-1 / 2}$ for both CON and NET_TFTs. 
As shown in Figure 8, $\sigma V_{T H}$ is clearly proportional to $(L W)^{-1 / 2}$. The slope of the linear-regression line for NET_TFTs is lower than that of CON_TFTs. $N_{E F F}$ and $W_{\text {dep }}$ are largely affected by the presence of GB traps. Thus, in the nanonet-channel structure, the effective reduction of GB traps and better gate controllability can lead to a thinner $W_{\text {dep }}$ and lower $N_{E F F}$. These results suggest that the nanonet-channel is very effective for reducing the variation of the device characteristics.

\section{Conclusions}

We successfully fabricated nanonet-channel LTPS TFTs using the NAP technique involving oxygen plasma treatment. The nanonet-channel TFTs demonstrated a lower SS and $\mathrm{V}_{\mathrm{TH}}$, higher ON/OFF current ratio, and a high immunity to hot carrier stress. Moreover, the nanonet-channel devices achieved a lowered variation of electrical characteristics, which was mainly attributed to the effective reduction of GB traps and enhanced gate controllability. These results indicate that the nanonet-channel TFTs using the NAP technology could be a promising solution for realizing mass production of high-performance TFT applications with a lower electrical variation.

Author Contributions: Conceptualization, G.Y. and I.P.; investigation, D.K.; methodology, D.K.; Data curation, B.J.; writing—original draft preparation, G.Y., B.J. and J.-S.L.; writing—review \& editing, G.Y. and J.-S.L.; supervision, J.-S.L. All authors have read and agreed to the published version of the manuscript.

Funding: This work was supported by the Korea Institute of Planning and Evaluation for Technology in Foog, Agriculture, Forestry, and Fisheries (IPET) through the Animal Disease Management Technology Develop-ment Program, which is funded by the Ministry of Agriculture, Food, and Rural Affairs (MAFRA)(120091-02-1-CG000) and by the Future Semiconductor Device Technology Development Program (10067739) funded by Ministry of Trade, Industry \& Energy (MOTIE) and Korea Semiconductor Rsearch Consortium (KSRC).

Conflicts of Interest: The authors declare that they have no conflict of interest.

\section{References}

1. Tai, Y.-H.; Kuo, Y.-F.; Lee, Y.-H. Photosensitivity Analysis of Low-Temperature Poly-Si Thin-Film Transistor Based on the Unit-Lux-Current. IEEE Trans. Electron. Devices 2009, 56, 50-56. [CrossRef]

2. Shih-Ching, C.; Ting-Chang, C.; Po-Tsun, L.; Yung-Chun, W.; Po-Shun, L.; Bae-Heng, T.; Jang-Hung, S.; Sze, S.M.; Chun-Yen, C.; Chen-Hsin, L. A Novel Nanowire Channel Poly-Si TFT Functioning as Transistor and Nonvolatile SONOS Memory. IEEE Electron. Device Lett. 2007, 28, 809-811. [CrossRef]

3. Goto, T.; Saito, K.; Imaizumi, F.; Hatanaka, M.; Takimoto, M.; Mizumura, M.; Gotoh, J; Ikenoue, H.; Sugawa, S. LTPS Thin-Film Transistors Fabricated Using New Selective Laser Annealing System. IEEE Trans. Electron. Devices 2018, 65, 3250-3256. [CrossRef]

4. Asano, A.; Kinoshita, T. 43.2: Low-Temperature Polycrystalline-Silicon TFT Color LCD Panel Made of Plastic Substrates. SID Symp. Dig. Tech. Pap. 2002, 33, 1196. [CrossRef]

5. Farmakis, F.V.; Brini, J.; Kamarinos, G.; Angelis, C.T.; Dimitriadis, C.A.; Miyasaka, M. On-current modeling of large-grain polycrystalline silicon thin-film transistors. IEEE Trans. Electron. Devices 2001, 48, 701-706. [CrossRef]

6. Tsai, C.-C.; Wei, K.-F.; Lee, Y.-J.; Chen, H.-H.; Wang, J.-L.; Lee, I.-C.; Cheng, H.-C. High-Performance Short-Channel Double-Gate Low-Temperature Polysilicon Thin-Film Transistors Using Excimer Laser Crystallization. IEEE Electron. Device Lett. 2007, 28, 1010-1013. [CrossRef]

7. Nakajima, Y.; Kida, Y.; Murase, M.; Toyoshima, Y.; Maki, Y. 21.3: Invited Paper: Latest Development of "System-on-Glass" Display with Low Temperature Poly-Si TFT. SID Symp. Dig. Tech. Pap. 2004, 35, 864. [CrossRef]

8. Stewart, M.; Howell, R.S.; Pires, L.; Hatalis, M.K. Polysilicon TFT technology for active matrix OLED displays. IEEE Trans. Electron. Devices 2001, 48, 845-851. [CrossRef]

9. Son, S.W.; Byun, C.W.; Lee, Y.W.; Yun, S.J.; Takaloo, A.V.; Park, J.H.; Joo, S.K. Effect of Dopant Concentration in Lightly Doped Drain Region on the Electrical Properties of N-Type Metal Induced Lateral Crystallization Polycrystalline Silicon Thin Film Transistors. Jpn. J. Appl. Phys. 2013, 52, 10MC13. [CrossRef]

10. Park, J.H.; Seok, K.H.; Kim, H.Y.; Chae, H.J.; Lee, S.K.; Joo, S.K. A Novel Design of Quasi-Lightly Doped Drain Poly-Si Thin-Film Transistors for Suppression of Kink and Gate-Induced Drain Leakage Current. IEEE Electron. Device Lett. 2015, 36, 351-353. [CrossRef]

11. Yamauchi, N.; Hajjar, J.-J.J.; Reif, R. Polysilicon thin-film transistors with channel length and width comparable to or smaller than the grain size of the thin film. IEEE Trans. Electron. Devices 1991, 38, 55-60. [CrossRef] 
12. Watakabe, H.; Sameshima, T. Polycrystalline silicon thin-film transistors fabricated by defect reduction methods. IEEE Trans. Electron. Devices 2002, 49, 2217-2221. [CrossRef]

13. Wang, A.W.; Saraswat, K.C. A strategy for modeling of variations due to grain size in polycrystalline thin-film transistors. IEEE Trans. Electron. Devices 2000, 47, 1035-1043. [CrossRef]

14. Kouvatsos, D.N.; Voutsas, A.T.; Hatalis, M.K. High-performance thin-film transistors in large grain size polysilicon deposited by thermal decomposition of disilane. IEEE Trans. Electron. Devices 1996, 43, 1399-1406. [CrossRef]

15. Wu, I.-W.; Huang, T.-Y.; Jackson, W.B.; Lewis, A.G.; Chiang, A. Passivation kinetics of two types of defects in polysilicon TFT by plasma hydrogenation. IEEE Electron. Device Lett. 1991, 12, 181-183. [CrossRef]

16. Chang-Ho, O.; Matsumura, M. A proposed single grain-boundary thin-film transistor. IEEE Electron. Device Lett. 2001, 22, 20-22. [CrossRef]

17. Yeh, M.-S.; Lee, Y.-J.; Hung, M.-F.; Liu, K.-C.; Wu, Y.-C. High-Performance Gate-All-Around Poly-Si Thin-Film Transistors by Microwave Annealing with NH3 Plasma Passivation. IEEE Trans. Nanotechnol. 2013, 12, 636-640. [CrossRef]

18. Sposili, R.S.; Im, J.S. Sequential lateral solidification of thin silicon films on $\mathrm{SiO}_{2}$. Appl. Phys. Lett. 1996, 69, 2864-2866. [CrossRef]

19. Wang, C.-L.; Lee, I.-C.; Wu, C.-Y.; Chou, C.-H.; Yang, P.-Y.; Cheng, Y.-T.; Cheng, H.-C. High-Performance Polycrystalline-Silicon Nanowire Thin-Film Transistors with Location-Controlled Grain Boundary via Excimer Laser Crystallization. IEEE Electron. Device Lett. 2012, 33, 1562-1564. [CrossRef]

20. Fukuzumi, Y.; Katsumata, R.; Kito, M.; Kido, M.; Sato, M.; Tanaka, H.; Nagata, Y.; Matsuoka, Y.; Iwata, Y.; Aochi, H.; et al. Optimal Integration and Characteristics of Vertical Array Devices for Ultra-High Density, Bit-Cost Scalable Flash Memory. In Proceedings of the 2007 International Electron Devices Meeting, Washington, DC, USA, 10-12 December 2007; pp. 449-452.

21. Lee, H.; Lee, J.; Baek, S.; Jeong, W.H.; Lee, Y.; Yang, T.; Lee, J.-S. Highly Enhanced Performance of Network Channel Polysilicon Thin-Film Transistors. IEEE Electron. Device Lett. 2017, 38, 187-190. [CrossRef]

22. Lee, J.; Lee, H.; Jin, B.; Oh, H.; Baek, S.; Yoon, G.; Lee, Y.; Baek, R.-H.; Lee, J.-S. Impact of geometrical parameters on the electrical performance of network-channel polycrystalline silicon thin-film transistors. Jpn. J. Appl. Phys. 2018, 57, 104001. [CrossRef]

23. Liou, J.-K.; Chen, C.-C.; Chou, P.-C.; Tsai, Z.-J.; Chang, Y.-C.; Liu, W.-C. Implementation of a High-Performance GaN-Based Light-Emitting Diode Grown on a Nanocomb-Shaped Patterned Sapphire Substrate. IEEE J. Quantum Electron. 2014, 50, 973-980. [CrossRef]

24. Sun, S.; Lu, P.; Xu, J.; Xu, L.; Chen, K.; Wang, Q.; Zuo, Y. Fabrication of Anti-reflecting Si Nano-structures with Low Aspect Ratio by Nano-sphere Lithography Technique. Nano-Micro Lett. 2013, 5, 18-25. [CrossRef]

25. Zhang, Y.; Geng, H.; Zhou, Z.; Wu, J.; Wang, Z.; Zhang, Y.; Li, Z.; Zhang, L.; Yang, Z.; Hwang, H. Development of Inorganic Solar Cells by Nano-technology. Nano-Micro Lett. 2012, 4, 124-134. [CrossRef]

26. Purwidyantri, A.; Kamajaya, L.; Chen, C.-H.; Luo, J.-D.; Chiou, C.-C.; Tian, Y.-C.; Lin, C.-Y.; Yang, C.-M.; Lai, C.-S. A Colloidal Nanopatterning and Downscaling of a Highly Periodic Au Nanoporous EGFET Biosensor. J. Electrochem. Soc. 2018, 165, H3170-H3177. [CrossRef]

27. Liang, X.; Dong, R.; Ho, J.C. Self-Assembly of Colloidal Spheres toward Fabrication of Hierarchical and Periodic Nanostructures for Technological Applications. Adv. Mater. Technol. 2019, 4, 1800541. [CrossRef]

28. Valsesia, A.; Meziani, T.; Bretagnol, F.; Colpo, P.; Ceccone, G.; Rossi, F. Plasma assisted production of chemical nano-patterns by nano-sphere lithography: Application to bio-interfaces. J. Phys. D Appl. Phys. 2007, 40, 2341-2347. [CrossRef]

29. Purwidyantri, A.; Chen, C.-H.; Hwang, B.-J.; Luo, J.-D.; Chiou, C.-C.; Tian, Y.-C.; Lin, C.-Y.; Cheng, C.-H.; Lai, C.-S. Spin-coated Au-nanohole arrays engineered by nanosphere lithography for a Staphylococcus aureus $16 \mathrm{~S}$ rRNA electrochemical sensor. Biosens. Bioelectron. 2016, 77, 1086-1094. [CrossRef]

30. Doyle, B.S.; Datta, S.; Doczy, M.; Hareland, S.; Jin, B.; Kavalieros, J.; Linton, T.; Murthy, A.; Rios, R.; Chau, R. High Performance Fully-Depleted Tri-Gate CMOS Transistors. IEEE Electron. Device Lett. 2003, 24, 263-265. [CrossRef]

31. Krutsick, T.J.; White, M.H.; Hon-Sum, W.; Booth, R.V.H. An improved method of MOSFET modeling and parameter extraction. IEEE Trans. Electron. Devices 1987, 34, 1676-1680. [CrossRef]

32. Ma, W.C.-Y.; Chiang, T.-Y.; Lin, J.-W.; Chao, T.-S. Oxide Thinning and Structure Scaling Down Effect of Low-Temperature Poly-Si Thin-Film Transistors. J. Disp. Technol. 2012, 8, 12-17. [CrossRef]

33. Levinson, J.; Shepherd, F.R.; Scanlon, P.J.; Westwood, W.D.; Este, G.; Rider, M. Conductivity behavior in polycrystalline semiconductor thin film transistors. J. Appl. Phys. 1982, 53, 1193-1202. [CrossRef]

34. Proano, R.E.; Misage, R.S.; Ast, D.G. Development and electrical properties of undoped polycrystalline silicon thin-film transistors. IEEE Trans. Electron. Devices 1989, 36, 1915-1922. [CrossRef]

35. Chen, C.-Y.; Lee, J.-W.; Wang, S.-D.; Shieh, M.-S.; Lee, P.-H.; Chen, W.-C.; Lin, H.-Y.; Yeh, K.-L.; Lei, T.-F. Negative Bias Temperature Instability in Low-Temperature Polycrystalline Silicon Thin-Film Transistors. IEEE Trans. Electron. Devices 2006, 53, $2993-3000$. [CrossRef]

36. Kow, M.C.; Yuan, H.C.; Gin, M.L.; Chi, G.D.; Jian, H.L. Enhanced degradation in polycrystalline silicon thin-film transistors under dynamic hot-carrier stress. IEEE Electron. Device Lett. 2001, 22, 475-477.

37. Takeuchi, K.; Tatsumi, T.; Furukawa, A. Channel engineering for the reduction of random-dopant-placement-induced threshold voltage fluctuations. In Proceedings of the 1996 International Electron Devices Meeting, Washington, DC, USA, 10 December 1997; pp. 841-844. 